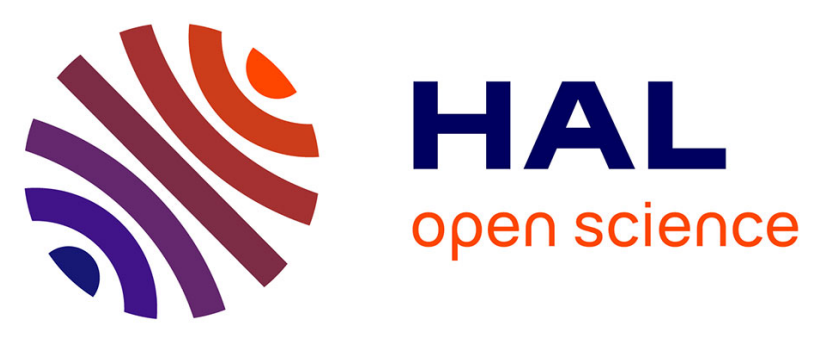

\title{
Influence of Capping Ligands on the Catalytic Performances of Cobalt Nanoparticles Prepared with the Organometallic Route
}

Kamila Kaźmierczak, Deliang Yi, Arnaud Jaud, Pier-Francesco Fazzini, Marta Estrader, Guillaume Viau, Philippe Decorse, J. Piquemal, Carine Michel, M.

Besson, et al.

\section{To cite this version:}

Kamila Kaźmierczak, Deliang Yi, Arnaud Jaud, Pier-Francesco Fazzini, Marta Estrader, et al.. Influence of Capping Ligands on the Catalytic Performances of Cobalt Nanoparticles Prepared with the Organometallic Route. Journal of Physical Chemistry C, 2021, 125 (14), pp.7711-7720. 10.1021/acs.jpcc.1c01388 . hal-03234465

\section{HAL Id: hal-03234465 \\ https://hal.science/hal-03234465}

Submitted on 7 Oct 2021

HAL is a multi-disciplinary open access archive for the deposit and dissemination of scientific research documents, whether they are published or not. The documents may come from teaching and research institutions in France or abroad, or from public or private research centers.
L'archive ouverte pluridisciplinaire HAL, est destinée au dépôt et à la diffusion de documents scientifiques de niveau recherche, publiés ou non, émanant des établissements d'enseignement et de recherche français ou étrangers, des laboratoires publics ou privés.

\section{(c) (1) $\$$}

Distributed under a Creative Commons Attribution - NonCommerciall 4.0 International 


\title{
Influence of Capping Ligands on the Catalytic Performances of Cobalt Nanoparticles Prepared with the Organometallic Route
}

\author{
Kamila Ká́mierczak, Deliang Yi, Arnaud Jaud, Pier-Francesco Fazzini, Marta Estrader, Guillaume Viau, \\ Philippe Decorse, Jean-Yves Piquemal, Carine Michel, Michèle Besson, Katerina Soulantica,* \\ and Noémie Perret*
}

\begin{abstract}
Cobalt nanorods and cobalt nanoplatelets, prepared by the same organometallic route with two different metal precursors, were tested for the first time in the acceptor-less dehydrogenation of 2-octanol. The nature of the metal precursor determines not only nanoparticle morphology but also their surface chemistry. While cobalt nanorods showed high conversions (up to $85 \%$ after $24 \mathrm{~h}$ ) and complete selectivity toward 2-octanone with concomitant molecular hydrogen production, cobalt nanoplatelets were practically inactive. Here, we show that this striking difference in the catalytic properties is not associated with facet-dependent differences in reactivity, but rather with different surface chemistry. The activity critically depends on the coordinating ability of the adsorbed species under catalytic reaction conditions and to a smaller degree on their concentration, as evidenced by ligand exchange experiments at room temperature as well as by direct addition of ligands in the reaction during catalysis by cobalt nanorods. This study shows that to optimize performances with unsupported metal nanocatalysts, the capping ligands should be selected by considering their ability to reversibly dissociate from the metal surface during catalysis.
\end{abstract}

\section{INTRODUCTION}

Economic and environmental concerns impose the constant development of catalytic systems with optimized activity, selectivity, and stability. Catalytic performances strongly depend on the structural characteristics of the particles. ${ }^{1,2}$ Wet chemistry methods for the synthesis of nanoparticles (NPs) are best suited for tuning NP size distribution, shape, and chemical composition. ${ }^{3}$ This control over structural characteristics is one of the key arguments for employing NPs prepared by solution approaches as catalysts. ${ }^{4-8}$ These methods of preparation invariably comprise capping agents, herein called ligands, as key components to achieve size and shape control, as well as colloidal stability. Ligands influence the catalytic performances of NP-based catalysts, via steric interactions and electronic modifications. But the role of the ligands is many-sided and controversial. ${ }^{9}$ Indeed, they can act as poisons, blocking active sites, or as reaction inhibitors, limiting substrate accessibility on the surface. ${ }^{10,11}$ In some cases, the ligands can be simple spectators. However, they can also behave as promoters, by selectively blocking sites or modifying reaction intermediates adsorption on the metal, leading to improved yields and unpredicted selectivity. ${ }^{12-19}$

Lately, cobalt has attracted attention as an alternative to noble metals in catalysis. Recently, it was used as the active phase of supported heterogeneous catalysts ${ }^{20,21}$ and in the form of unsupported shape-controlled $\mathrm{NPs}^{22-24}$ for the acceptor-less alcohol dehydrogenation (AAD). This is an interesting reaction, since from an alcohol, only the corresponding carbonyl compound and $\mathrm{H}_{2}$ are obtained. Supported cobalt catalysts were shown to be active in the dehydrogenation of secondary alcohols, including 2-octanol. ${ }^{20,21}$ However, the reactions were not completely selective to 2-octanone and $\mathrm{H}_{2}$ due to the formation of small amounts of $\mathrm{C} 16$ byproducts, resulting from aldol condensation/ dehydration reactions, followed by subsequent hydrogenation. ${ }^{20}$ On the other hand, shape-controlled unsupported Co NPs were highly selective in the former reaction. ${ }^{22-24}$ These nano-objects were active when their ligand surface coverage was limited to one to two monolayers. ${ }^{22}$ Furthermore, density functional theory (DFT) computations showed that carboxylic ligands affect the reaction. They stabilize the substrate adsorption through $\mathrm{H}$-bonding, but they also generate steric hindrance, which destabilizes the adsorption of reaction 
intermediates and products, hence facilitating desorption. The shape sensitivity of the reaction was also evidenced as nanorods, exposing mainly $\{11 \overline{2} 0\}$ facets, were more active than nanodiabolos and nanocubes. ${ }^{23,24}$ In those studies, ${ }^{22-25}$ the NPs were synthesized by the polyol method, in the presence of carboxylic ligands. Nevertheless, the influence of the nature of the ligands on the catalytic properties of Co NPs in $\mathrm{AAD}$ reaction has never been investigated.

Besides the well-established polyol process, ${ }^{26}$ another approach for the synthesis of shaped NPs is the organometallic method. ${ }^{27,28}$ This method has been employed for the synthesis of Co nanorods (NRs), using a mixture of long-chain carboxylic acid and long-chain amine as shape-directing and capping agents. ${ }^{29-31}$ Slight modification of the preparation conditions, for example, change of the metal precursor and/or type and proportion of the ligands result in modifications of the size and shape, ${ }^{32-34}$ as well as surface chemistry of the nano-objects obtained. The aforementioned structural changes may influence the activity and/or selectivity of the obtained NPs. ${ }^{2,16,35}$

Here, we compare the catalytic activity of Co nano-objects exposing different crystallographic facets and different surface chemistry in the $\mathrm{AAD}$ of 2-octanol, and we investigate the effect of the nature and the amount of the capping ligands on the reaction. Co NRs and Co nanoplatelets (NPLs) are obtained by reduction under $\mathrm{H}_{2}$ in the presence of lauric acid (LA) and hexadecylamine (HDA) of the precursors $[\mathrm{Co}\{\mathrm{N}$ $\left.\left(\mathrm{SiMe}_{3}\right)_{2}\right\}_{2}($ thf $\left.)\right]($ thf $=$ tetrahydrofurane $)$ and $\left[\mathrm{CoCl}\left(\mathrm{PPh}_{3}\right)_{3}\right]$ $(\mathrm{Ph}=$ phenyl $)$, respectively. While the different crystallographic facets exposed on NRs and NPLs do not play a determinant role, postsynthesis ligand exchanges as well as addition of ligand excess in the catalytic reaction mixture show that both chloride ions and excess of carboxylate ligands are detrimental for the catalytic activity. However, compared to previously reported results with Co NRs stabilized only by laurate species, we also show here that a very significant improvement of the catalytic activity can be achieved when a mixture of hexadecylamine and hexadecyl laurylamide native ligands is present at the particle surface.

\section{METHODS}

Materials. Due to the air sensitivity of the metal precursors and of the resulting nanocrystals, synthesis of the Co nanoparticles was performed under Ar, either in a glovebox or by employing standard Schlenk techniques. Hexadecylamine (HDA, 98\%, Sigma-Aldrich) and lauric acid (LA, 99\%, Acros Organics) were transferred into the glovebox and used without further purification. Toluene (99\%, Fisher) and pentane (99\%, Fisher) were purified by a solvent purifier (Innovative Technology Purification System), degassed by Ar bubbling, and then kept in the glovebox over activated molecular sieves. Anhydrous anisole, packed and furnished under an inert atmosphere, was purchased from Aldrich (99.7\%, anhydrous). It was transferred to the glovebox, and the traces of water were removed by activated molecular sieves. $[\mathrm{Co}\{\mathrm{N}$ $\left.\left.\left(\mathrm{SiMe}_{3}\right)_{2}\right\}_{2}(\mathrm{thf})\right]$ (thf = tetrahydrofurane $)^{29}$ was purchased from NanoMeps and kept in the glovebox freezer. [CoCl$\left.\left(\mathrm{PPh}_{3}\right)_{3}\right]^{34}$ and $\mathrm{HDA} \cdot \mathrm{HCl}^{36}$ were prepared according to published procedures.

The following products were used in the catalytic tests: ( \pm )-2-octanol (98\%, Alfa Aesar), 2-octanone ( $\geq 99.5 \%$, SigmaAldrich), $n$-decane $\left(\geq 99 \%\right.$, Carl Roth), gaseous $\mathrm{N}_{2}$
( $\geq 99.999 \%$, Messer), and Ar ( $\geq 99.999 \%$, Air Liquide). All of them were used as received, without any further purification.

Synthesis Procedures. The cobalt nanorods (Co-NRs-I) were obtained according to an already published synthesis procedure, $^{31}$ by adaptation of the conditions to scale up the standard synthesis. In a glovebox, HDA (20.5 g; $85.1 \mathrm{mmol})$ dissolved in $520 \mathrm{~mL}$ of toluene and LA (10.5 g; $52.5 \mathrm{mmol}$ ) dissolved in $450 \mathrm{~mL}$ toluene were mixed in a $2 \mathrm{~L}$ volume double-wall Fischer-Porter reactor and vigorously stirred for 3 min. The precursor $\left[\mathrm{Co}\left\{\mathrm{N}\left(\mathrm{SiMe}_{3}\right)_{2}\right\}_{2}(\mathrm{thf})\right](22.6 \mathrm{~g} ; 50.0$ $\mathrm{mmol}$ ) dissolved in $30 \mathrm{~mL}$ of toluene was added to the HDALA mixture under vigorous stirring. The Fischer-Porter reactor was sealed and transferred to a vacuum line, where Ar was evacuated. The reactor was then pressurized up to 3 bar of $\mathrm{H}_{2}$ and the mixture was stirred for $7 \mathrm{~min}$ at room temperature. It was then connected to a heating circulator bath that was thermally equilibrated at $110^{\circ} \mathrm{C}$. After $24 \mathrm{~h}$ of reaction under $\mathrm{H}_{2}$ and stirring at $110{ }^{\circ} \mathrm{C}$, the reactor was disconnected from the heating bath and cooled down before being introduced into the glovebox to purify the Co NRs. The dark suspension was allowed to stand, the dark brown supernatant was removed, and $300 \mathrm{~mL}$ of toluene was added; then, the mixture was stirred and decanted again. The brown supernatant was removed, and the washing procedure was repeated until the supernatant became completely colorless. Subsequent washing three times with pentane allowed elimination of toluene to facilitate drying in the glovebox.

Co-NRs-II were prepared by the same procedure. The washing cycles with toluene were stopped when the color of the transparent supernatant was yellow-brown. In this case, it is expected that the residual ligand amount adsorbed onto Co is higher than onto Co-NRs-I.

The Co nanoplatelets (Co-NPLs) were obtained by reduction under pressurized $\mathrm{H}_{2}$ of the precursor [CoCl$\left(\mathrm{PPh}_{3)_{3}}\right]$ in the presence of HDA and LA. In a typical reaction, HDA (1.40 g; $5.8 \mathrm{mmol})$ in $55 \mathrm{~mL}$ of anisole and LA (0.82 g; $4.1 \mathrm{mmol})$ in $35 \mathrm{~mL}$ of anisole were mixed in a Fischer-Porter reactor under vigorous stirring. After $3 \mathrm{~min}, \operatorname{CoCl}\left[\mathrm{P}\left(\mathrm{Ph}_{3}\right)\right]_{3}$ (3.00 g; $3.4 \mathrm{mmol})$ in $10 \mathrm{~mL}$ of anisole was added to the stirred HDA-LA mixture. The Fischer-Porter reactor was sealed and transferred to a vacuum line, where the Ar was evacuated. The reactor was then pressurized up to 3 bar of $\mathrm{H}_{2}$, and the mixture was stirred for $7 \mathrm{~min}$ at room temperature. It was then placed in an oil bath preheated at $150{ }^{\circ} \mathrm{C}$ under vigorous stirring for $24 \mathrm{~h}$. After cooling down, the reactor was transferred to the glovebox and the suspension was allowed to stand. The brown supernatant was removed. The precipitate was first washed three times with $30 \mathrm{~mL}$ of toluene at room temperature (until the supernatant became colorless) and then three times with $20 \mathrm{~mL}$ of hot toluene $\left(60{ }^{\circ} \mathrm{C}\right)$. Washing three times with pentane allowed eliminating toluene to facilitate drying in the glovebox.

Ligand Exchange Procedure. The ligand exchange procedures were carried out in a glovebox. In a typical reaction for ligand exchange with HDA (Co-NRs-I-HDA-Ex), $0.300 \mathrm{~g}$ of Co nanorods (Co-NRs-I), $0.200 \mathrm{~g}$ HDA, and $20 \mathrm{~mL}$ of toluene were mixed together. The solution was sonicated for 2 min in an ultrasound bath and kept under stirring overnight. Then, the solution was kept still until the particles settled down and the supernatant became clear. After that, the supernatant was removed. The whole procedure was repeated a second time, and the final product was washed with $20 \mathrm{~mL}$ of 

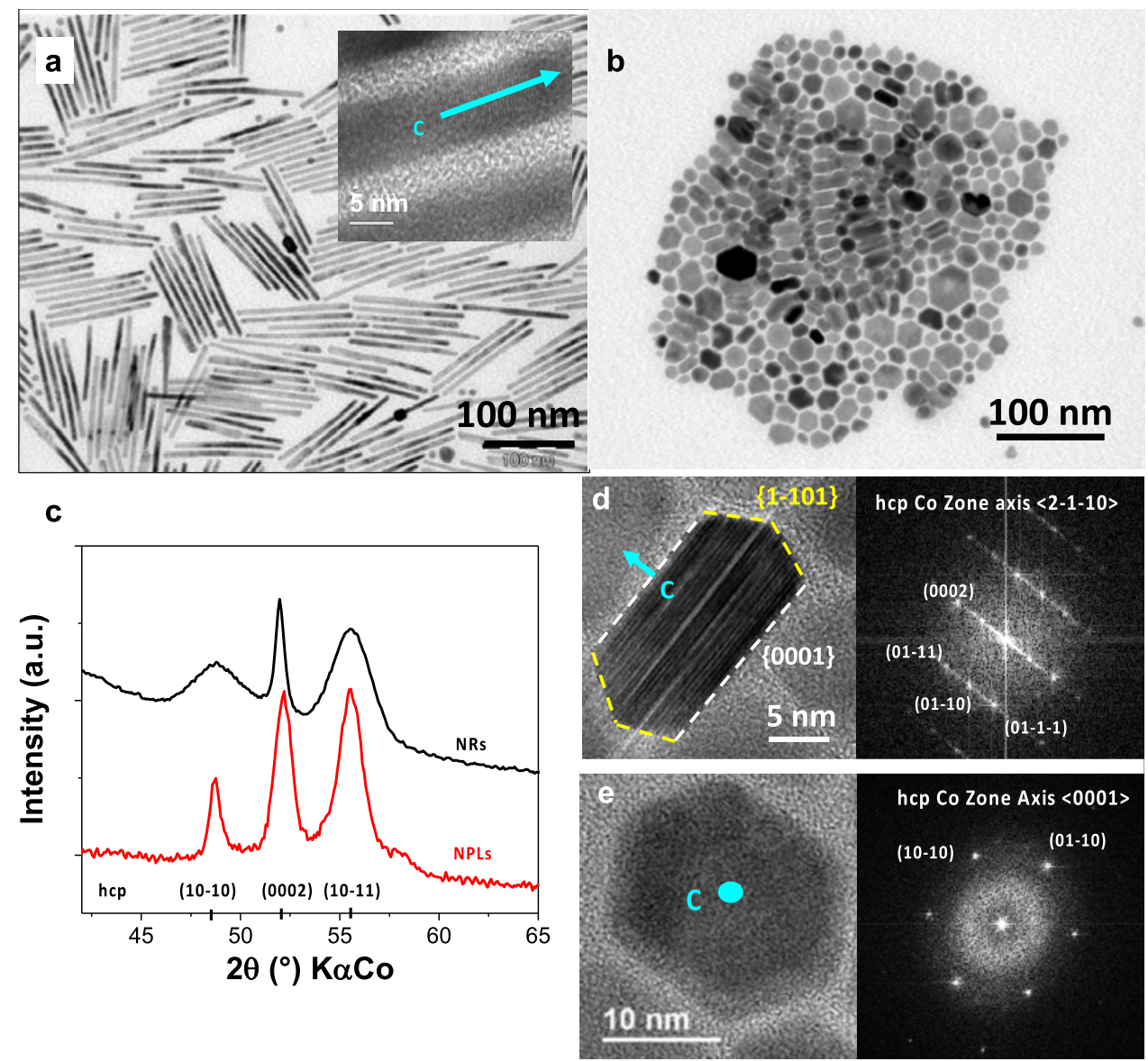

Figure 1. (a) TEM images of Co-NRs-I (scale bar: $100 \mathrm{~nm}$ ); inset: HRTEM image (scale bar: $5 \mathrm{~nm}$ ) and $c$ axis orientation in cyan. (b) TEM image of Co-NPLs (scale bar: $100 \mathrm{~nm}$ ). (c) XRD patterns for Co-NRs-I (black line) and Co-NPLs (red line). (d) HRTEM image (scale bar: 5 $\mathrm{nm}$ ) and the corresponding Fourier transform of a Co-NPL (side view). (e) HRTEM image (scale bar: $10 \mathrm{~nm}$ ) and the corresponding Fourier transform of a Co-NPL along the $c$ axis. The object and facets orientation were determined from the Fourier transforms.

pentane and dried overnight by letting the pentane residues evaporate in the glovebox.

For the ligand exchange with LA (Co-NRs-I-LA-Ex), the procedure was the same except $0.200 \mathrm{~g}$ of LA was used instead of $0.200 \mathrm{~g}$ of HDA.

Characterization Methods. X-ray diffraction (XRD) patterns of particles, encapsulated between two kapton foils, were recorded on a Panalytical Empyrean diffractometer equipped with a Co $\mathrm{K} \alpha \mathrm{X}$-ray source. X-ray photoelectron spectroscopy (XPS) spectra were recorded using a K-alpha plus system (Thermo Fisher Scientific, East-Grinstead, U.K.) fitted with a micro-focused and monochromatic $\mathrm{Al} \mathrm{K} \alpha \mathrm{X}$-ray source $(1486.6 \mathrm{eV}$, spot size of $400 \mu \mathrm{m})$. The spectrometer pass energy was set to 150 and $40 \mathrm{eV}$ for the survey and the narrow high-resolution regions, respectively. Several drops of colloidal suspensions were deposited on a silicon substrate and dried in the glovebox. Thermogravimetric analysis (TGA) measurements were performed with a TGA-DSC 1 Star $^{\mathrm{e}}$ System Mettler Toledo apparatus, in the temperature range of $20-1000{ }^{\circ} \mathrm{C}$, using $10^{\circ} \mathrm{C} \mathrm{min}{ }^{-1}$ heating rate and $50 \mathrm{~mL}$ $\mathrm{min}^{-1}$ of $\mathrm{N}_{2}$. The as-obtained organic ligands content of the nanoparticles (\% ligands, wt \%) corresponds to the weight loss at $500{ }^{\circ} \mathrm{C}$ (uncertainty $\pm 0.2 \%$ ). Elemental analyses $(\mathrm{C}, \mathrm{H}, \mathrm{N}$ ) were performed using an organic elemental analyzer PerkinElmer 2400 (serie II) instrument (uncertainty $\pm 0.1 \%$ ), on isolated powder samples weighed under inert conditions. The cobalt content was determined by inductively coupled plasma (ICP) analysis (uncertainty, $\pm 0.1 \%$ ), performed by Mikroanalytisches Laboratorium Kolbe. Conventional transmission electron microscopy (TEM) characterizations were performed using a Jeol JEM-1011 instrument equipped with a $\mathrm{W}$ thermionic electron source and operating at $100 \mathrm{kV}$. The images were collected with a SIS camera (Magaview III). The NR diameters were determined only by more than 100 measurements due to the very small variation. The other mean particle sizes were determined by a statistical analysis of at least 300 particles. The high-resolution TEM (HRTEM) analysis was carried out using a JEOL JEM 2100F microscope, equipped with a field emission gun (FEG) and a Gatan Ultrascan 1000 CCD camera and operating at an acceleration voltage of $200 \mathrm{kV}$. All samples were prepared by evaporating a drop of diluted suspension in toluene or in ethanol on a carbon-coated copper grid. Specific surface areas (SSAs) exposed by metal in the samples were calculated using the mean dimensions determined by TEM and assuming simple geometrical models.

SSA Calculation. The specific surface area exposed by metal, SSA $=S_{\text {tot }} / m=S_{\text {tot }} / d_{\mathrm{Co}} V$ (uncertainty $\pm 2 \mathrm{~m}^{2} \mathrm{~g}^{-1}$ ), was calculated assuming a density of Co $\left(d_{\mathrm{Co}}\right)$ of $8.86 \mathrm{~g} \mathrm{~cm}^{-3}$. The volume of a nanoparticle $(V)$ and the surface area of a nanoparticle $\left(S_{\text {tot }}\right)$ can be calculated according to geometrical considerations (see the Supporting Information (SI)).

Ligands Surface Coverage Calculation. For a given sample, the coverage with organic ligands, ligand coverage $=$ 
Table 1. Main Characterization of Co-NRs-I, Co-NPLs, and Co-NRs-II ${ }^{a}$

\begin{tabular}{|lcccccccc}
\hline \multicolumn{1}{c}{ catalyst } & $L_{\mathrm{TEM}}(\mathrm{nm})$ & $d_{\mathrm{TEM}}(\mathrm{nm})$ & $\mathrm{SSA}\left(\mathrm{m}^{2} \mathrm{~g}^{-1}\right)$ & $\%$ ligands $(\mathrm{wt} \%)$ & $\% \mathrm{~N}(\mathrm{wt} \%)$ & $\mathrm{N} / \mathrm{C}$ at $\times 100$ & ligand coverage $\left(\mathrm{mg} \mathrm{m}^{-2}\right)$ \\
\hline Co-NRs-I & $107 \pm 6$ & $6.0 \pm 0.6$ & 89 & 12.9 & 0.34 & 3.0 & 1.7 \\
Co-NPLs & $12 \pm 1$ & $24 \pm 5$ & 70 & 17.7 & 0.30 & 5.6 & 3.1 \\
Co-NRs-II & $114 \pm 12$ & $5.8 \pm 0.5$ & 89 & 26.2 & 0.43 & 3.2 & 4.0
\end{tabular}

${ }^{a} L_{\text {TEM }}$ : TEM-derived mean length; $d_{\text {TEM }}$ : TEM-derived mean diameter; SSA: calculated specific surface area; \% ligands: the ligand content in the sample derived from TGA for Co NRs and from ICP analysis for Co-NPLs (the TGA weight loss for Co-NPLs was not stabilized even at $800{ }^{\circ} \mathrm{C}$; hence, in this case, it was determined by subtraction of Co content established in ICP analysis); \% N: elemental analysis-derived wt \% of N; N/C at $\times$ 100: N/C atomic ratio derived from elemental analysis, multiplied by 100 .

$($ wt $\%$ ligands $/ 100) /($ SSA $\times(1-$ wt $\%$ ligands/100 $))$, was evaluated as the ratio between the amount of ligands (based on TGA) and the specific surface area (based on TEM analysis).

Catalytic Tests. Dehydrogenation of 2-octanol was performed using Co NPs dispersed in $n$-decane. In a typical test, $25 \mathrm{mg}$ of Co NPs was placed into a reactor (glass, semibatch, $100 \mathrm{~mL}$ volume) inside a glovebox and covered with $30 \mathrm{~mL}$ of solvent. For the tests with direct addition of ligands, masses of ligand between ca. 0.9 and $25 \mathrm{mg}$ (HDA, $\mathrm{LA}$, or hexadecylamonium chloride $\mathrm{HDA} \cdot \mathrm{HCl}$ ) were added at the same time as the catalyst, before addition of the solvent. The reactor was closed and heated up to $145{ }^{\circ} \mathrm{C}$ under constant flow of inert gases $\left(10 \% \mathrm{v} / \mathrm{v} \mathrm{N}_{2} / \mathrm{Ar}, 30 \mathrm{~mL} \mathrm{~min}^{-1}\right)$ and with mechanical stirring $(750 \mathrm{rpm})$. When the desired temperature was reached, appropriate amounts of alcohol and solvent were added, to achieve a final reaction solution volume of $45 \mathrm{~mL}$, with an alcohol concentration of $0.95 \mathrm{~mol} \mathrm{~L}^{-1}$. The reactions were carried out for $24 \mathrm{~h}$.

Reaction Progress Monitoring. Reaction progress was followed by online analysis of the reaction gases mixture and by analysis of liquid aliquots collected periodically during the reaction. The outlet of gases from the reactor was coupled with a gas chromatograph (Shimadzu GC-2010, Supelco Carboxen1010 PLOT column $30 \mathrm{~m} \times 0.53 \mathrm{~mm}$; thermal program: isotherm, $50{ }^{\circ} \mathrm{C}, \mathrm{Ar}$ as a carrier gas, TCD detector). $\mathrm{N}_{2}$ was used as an internal standard for $\mathrm{H}_{2}$ measurement, whose quantification was based on the ratio between the integrations of these two signals, after calibration. Liquid samples were also analyzed by gas chromatography (Shimadzu GC-2010, column ZB-FFAP $30 \mathrm{~m} \times 0.32 \mathrm{~mm} \times 0.25 \mu \mathrm{m}$, thermal program: 40 ${ }^{\circ} \mathrm{C} \rightarrow 230^{\circ} \mathrm{C}, 20^{\circ} \mathrm{C} \min ^{-1}, 230^{\circ} \mathrm{C}, 10 \mathrm{~min}, \mathrm{~N}_{2}$ as carrier gas, FID detector) to evaluate the alcohol and 2-octanone (product) concentrations in solution, after calibration.

Results Analysis. The conversion of the substrate $X(\%)=$ $\left(1-C_{x} / C_{0}\right) \times 100$ (uncertainty $\left.\pm 3 \%\right)$ is based on the concentration of 2 -octanol at a given time in liquid aliquot $\left(C_{x}\right)$ and the concentration of 2-octanol at the beginning of the reaction $\left(C_{0}\right)$. The selectivity toward the corresponding ketone $S(\%)=C_{2 \text {-octanone }} /\left(C_{2 \text {-octanone }}+\sum n C_{\text {by-product }}\right) \times 100$ is based on the concentration of 2 -octanone $\left(C_{2 \text {-octanone }}\right)$ and byproduct $\left(C_{\text {by-product }}\right)$ at a given time in liquid aliquot, and $n$ is a stoichiometric coefficient. The turnover number TON = $n_{\text {converted substrate }} / n_{\text {surface Co atoms }}$ is calculated with an uncertainty of $\pm 75 \mathrm{~mol}_{\text {alcohol }} \mathrm{mol}_{\text {surface Co }}{ }^{-1}$. The amount of surface Co (first layer of metal) in the catalyst sample used in the reaction ( $\left.n_{\text {surface Co atoms }}\right)$ was evaluated taking into account that the exposed facets exhibit different amounts of Co atoms per surface unit, according to the following formula

$$
\begin{aligned}
n_{\text {surface Co atoms }}= & \text { SA } \times\left\{\left(\frac{\%(0001)}{100} \cdot \delta_{\mathrm{Co}(0001)}\right)\right. \\
& +\left(\frac{\%(11 \overline{2} 0)}{100} \cdot \delta_{\mathrm{Co}(11 \overline{2} 0)}\right) \\
& \left.+\left(\frac{\%(10 \overline{1} 1)}{100} \cdot \delta_{\mathrm{Co}(10 \overline{1} 1)}\right)\right\}
\end{aligned}
$$

with $\delta_{\mathrm{Co}(0001)}=31.42 \times 10^{-6} \mathrm{~mol}_{\mathrm{Co}} \mathrm{m}^{-2}, \delta_{\mathrm{Co}(11 \overline{2} 0)}=19.35 \times$ $10^{-6} \mathrm{~mol}_{\mathrm{Co}} \mathrm{m}^{-2}, \delta_{\mathrm{Co}(10 \overline{1} 1)}=15.09 \times 10^{-6} \mathrm{~mol}_{\mathrm{Co}} \mathrm{m}^{-2}$, and SA, the surface of exposed metallic Co (definition in the SI).

\section{RESULTS AND DISCUSSION}

Co NPs Morphology. Co nanorods Co-NRs-I were synthesized by reduction of $\left[\mathrm{Co}\left\{\mathrm{N}\left(\mathrm{SiMe}_{3}\right)_{2}\right\}_{2}(\right.$ thf $\left.)\right]$ under $\mathrm{H}_{2}$ in the presence of HDA and LA. The average length and diameter of Co-NRs-I were $107 \pm 6$ and $6.0 \pm 0.6 \mathrm{~nm}$, respectively, as measured from their TEM micrographs over at least 300 nanoparticles (Figures 1a and S1). Co nanoplatelets (Co-NPLs) were synthesized for the first time using $\left[\mathrm{CoCl}\left(\mathrm{PPh}_{3}\right)_{3}\right]$ as a precursor. Except for the nature of the precursor, the reaction conditions were very similar to the ones employed for the Co NRs (see the Methods section). Figure $1 \mathrm{~b}$ presents a TEM image of the Co-NPLs obtained with the same ligands as for the synthesis of Co-NRs-I. The mean diameter and thickness were measured from TEM micrographs to be $24 \pm 5$ and $12 \pm 1 \mathrm{~nm}$, respectively.

As evidenced by the XRD patterns, both Co-NRs-I and CoNPLs crystallize in the hexagonal close-packed (hcp) structure (Figure 1c). For the Co-NRs-I (Figure 1c, black line), the strong crystalline anisotropy is revealed by the difference of broadening of the (hkil) reflections of their XRD pattern. The

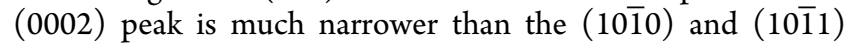
peaks, in agreement with rod growth along the $c$ axis of the hcp structure, as confirmed by the HRTEM image (inset in Figure 1a). The crystallite size $L_{(10 \overline{0})}$ calculated from the Scherrer formula $(4.5 \mathrm{~nm})$ is very close to the rod diameter $(6.0 \pm 0.6$ $\mathrm{nm})$. The crystallite size $L_{(0002)}$ is found to be equal to $25 \mathrm{~nm}$. This value is lower than the rod length $(107 \pm 6 \mathrm{~nm})$, suggesting the existence of a few crystallites along the $c$ axis, in agreement with the contrast of the TEM images. For the CoNPLs, the crystallite sizes $\left(L_{(10 \overline{1} 0)}\right.$ and $\left.L_{(0002)}\right)$, calculated from the XRD line broadening, were found to be equal to 16 and 10 $\mathrm{nm}$, respectively (Figure 1c, red line). These values are very close to the platelet diameter and thickness, respectively. Such an anisotropy shows that the platelets grow preferentially perpendicularly to the $c$ axis of the hcp structure, as confirmed by the HRTEM images (Figure 1d,e). Both nano-objects expose (0001) basal planes: the $c$ axis of the hcp phase coincides with the long axis of Co-NRs-I, and the short axis of the Co-NPLs. It has to be noted also that the Co-NRs-I expose 
$\{11 \overline{2} 0\}$-type lateral facets, ${ }^{31}$ whereas the Co-NPLs expose $\{1 \overline{1} 01\}$-type lateral facets. Thus, under similar synthesis conditions, a radical modification of the nanoparticle morphology is observed upon changing the Co precursor from $\left[\mathrm{Co}\left\{\mathrm{N}\left(\mathrm{SiMe}_{3}\right)_{2}\right\}_{2}(\right.$ thf $\left.)\right](\mathrm{Co}-\mathrm{NRs}-\mathrm{I})$ to $\left[\mathrm{CoCl}\left(\mathrm{PPh}_{3)_{3}}\right]\right.$ (Co-NPLs). In fact, the employment of $[\mathrm{Co}\{\mathrm{N}$ $\left.\left(\mathrm{SiMe}_{3}\right)_{2}\right\}_{2}$ (thf)] as a precursor, under exactly the same conditions as the ones used for Co-NPLs, gives rise to NRs (not shown here), which confirms the crucial influence of the precursor on the morphology.

The specific surface area (SSA) of Co-NRs-I was evaluated to be $89 \mathrm{~m}^{2} \mathrm{~g}^{-1}$ with only a very small percentage of (0001)type facets being exposed (less than 3\%), while Co-NPLs present an SSA of $70 \mathrm{~m}^{2} \mathrm{~g}^{-1}, 18 \%$ of which corresponds to (0001)-type facets and the rest to $\{1 \overline{1} 01\}$-type facets (Table 1 ; specific calculations are available in the SI). The washing steps only partially remove the native stabilizing agents. As the residual ligands may impact the catalytic performances, their amount and nature have to be considered when interpreting the results of the catalytic tests. According to the TGA and ICP analyses (Table 1), the content of ligands (wt \% ligands) and the ligand coverage ( $\mathrm{mg}$ of ligands per $\mathrm{m}^{2}$ of surface) after washing were lower on Co-NRs-I than on Co-NPLs, suggesting a better efficiency of the washing procedure for ligand removal in the case of Co-NRs-I. Elemental analysis revealed the presence of $\mathrm{N}$-containing species on the surfaces of both nanoparticles, which can be attributed to HDA-based residues.

Catalytic Performances and Surface Chemistry of the Co NPs. Both types of Co nano-objects (Co-NRs-I and CoNPLs) were tested in acceptor-less 2-octanol dehydrogenation, and the obtained results are presented in Table 2. The catalyst performance is expressed in conversion $(X \%)$ and turnover number (TON). It has to be noted that the TONs were calculated with respect to the amount of surface $\mathrm{Co}$, which was evaluated by geometrical considerations based on TEM observations. Co-NRs-I converted $85 \%$ of the substrate after

Table 2. Catalytic Acceptor-Less 2-Octanol Dehydrogenation $^{a}$

\begin{tabular}{|c|c|c|c|c|c|c|}
\hline entry & catalyst & $\begin{array}{l}\text { added } \\
\text { ligand }\end{array}$ & $\left(\mathrm{mmol}_{\text {ligands }} \mathrm{L}_{\mathrm{n}} \mathrm{g}_{\mathrm{NPs}}^{-1}\right)$ & $\begin{array}{c}X \\
(\%)\end{array}$ & $S(\%)$ & $\begin{array}{c}\text { TON } \\
(/ 24 \mathrm{~h})\end{array}$ \\
\hline 1 & Co-NRs-I & none & n.a. & 85 & $>99.99$ & 920 \\
\hline 2 & Co-NPLs & none & n.a. & 2 & n.a. & n.a. \\
\hline 3 & Co-NRs-II & none & n.a. & 70 & $>99.99$ & 860 \\
\hline 4 & $\begin{array}{l}\text { Co-NRs-II- } \\
\text { HDA. } \\
\text { HCl }\end{array}$ & $\begin{array}{l}\mathrm{HDA} \cdot \\
\mathrm{HCl}\end{array}$ & 4.67 & 2 & n.a. & n.a. \\
\hline 5 & $\begin{array}{l}\text { Co-NRs-II- } \\
\text { HDA }\end{array}$ & HDA & 4.67 & 73 & $>99.99$ & 920 \\
\hline 6 & $\begin{array}{c}\text { Co-NRs-II- } \\
\text { LA-4.7 }\end{array}$ & LA & 4.67 & 0 & n.a. & n.a. \\
\hline 7 & $\begin{array}{c}\text { Co-NRs-II- } \\
\text { LA-1.2 }\end{array}$ & LA & 1.17 & 1 & n.a. & n.a. \\
\hline 8 & $\begin{array}{c}\text { Co-NRs-II- } \\
\text { LA-0.6 }\end{array}$ & LA & 0.58 & 1 & n.a. & n.a. \\
\hline 9 & $\begin{array}{c}\text { Co-NRs-II- } \\
\text { LA-0.2 }\end{array}$ & LA & 0.23 & 72 & $>99.99$ & 920 \\
\hline
\end{tabular}

${ }^{a}$ Reaction conditions: $25 \mathrm{mg}$ of catalyst, substrate: $0.95 \mathrm{~mol} \mathrm{~L}^{-1} 2$ octanol, solvent: decane, $24 \mathrm{~h}, 145^{\circ} \mathrm{C}, V_{\text {total }}=45 \mathrm{~mL}, L_{\mathrm{n}}$ : number of moles of ligand externally added at the beginning of the reaction per gram of nanoparticles (NPs), $X$ : conversion, $S$ : selectivity to 2octanone, TON $(/ 24 \mathrm{~h})$ : turnover number $\left(\mathrm{mol}_{\text {alcohol }} \mathrm{mol}_{\text {surface Co }}{ }^{-1}\right)$ after $24 \mathrm{~h}, \pm 75 \mathrm{~mol}_{\text {alcohol }} \mathrm{mol}_{\text {surface Co }}{ }^{-1}$, n.a.: not applicable.
$24 \mathrm{~h}$ of reaction, with total selectivity toward ketone (2octanone) and $\mathrm{H}_{2}$ (Table 2, entry 1 ). The production of $\mathrm{H}_{2}$ was confirmed by on-line GC analysis of reaction gases. As an example, the temporal evolution of the conversion of 2octanol, yield of 2-octanone, and production of $\mathrm{H}_{2}$ in the presence of Co-NRs-I are shown in Figure S2. For the other catalysts, the data are presented in Figure S3. In terms of conversion, Co-NRs-I exhibit better performance compared to the one of laurate-protected Co nanorods ( $X=30-55 \%)$ prepared by the polyol method reported previously and tested under identical conditions. ${ }^{22}$ This could be associated with the different surface chemistry, hence accessibility to the surface, since HDA and LA are used for the preparation of Co NRs prepared with the organometallic pathway, while only LA is used for NRs prepared by the polyol process. It is also worth noting that the selectivity to 2-octanone remained complete, even at a high conversion, which was not the case for supported Co catalysts. ${ }^{20}$

Surprisingly, Co-NPLs were practically inactive. This result cannot be explained by a facet-dependent reactivity. As it was already shown, ${ }^{22}$ laurate-protected Co platelets and nanorods, exposing $(11 \overline{2} 0)$ and (0001) facets in distinct proportions, showed comparable activity in 2-octanol dehydrogenation, due to the presence of laurate ligands that attenuates the predicted structure sensitivity of ligand-free facets. Therefore, even if we consider the $\{1 \overline{1} 01\}$ facets of Co-NPLs as completely inactive, Co-NPLs should present a reduced, albeit non-negligible activity due to the remaining $18 \%$ of (0001) facets. Therefore, the striking difference in activity between NRs and NPLs should be due to their different facet passivation.

Both the amount and the nature of the capping organic ligands could play a role in determining the NP reactivity. First, we aimed at evaluating the role of the ligand amount, that is, the nanorod ligand coverage. For this, another batch of nanorods (Co-NRs-II) was prepared in an independent synthesis. Co-NRs-II were less extensively washed (see Table 1, entry 3, for characterization results and Figure S4 for TEM image). Co-NRs-I and Co-NRs-II exhibit the same morphology and similar average size; however, Co-NRs-II are protected with a higher amount of ligands, as it was aimed. The performances of Co-NRs-I and Co-NRs-II were then compared in the acceptor-less 2-octanol dehydrogenation (Table 2 , entry 1 vs entry 3 ). Co-NRs-II are also completely selective to 2-octanone. After $24 \mathrm{~h}$, the activity of Co-NRs-II was found to be $860 \mathrm{~mol}_{\text {alcohol }} \mathrm{mol}_{\text {surface Co }}{ }^{-1}$, which is slightly inferior to that of Co-NRs-I (920 mol alcohol $\left.\mathrm{mol}_{\text {surface Co }}{ }^{-1}\right)$, but within experimental error $\left( \pm 75 \mathrm{~mol}_{\text {alcohol }} \mathrm{mol}_{\text {surface }} \mathrm{Co}^{-1}\right)$. TEM analysis of Co-NRs-I and Co-NRs-II recovered after experiment (Figure S5 and Table S1) showed a slight aggregation. Moreover, a small decrease of the mean lengths (from 107 to $102 \mathrm{~nm}$ for Co-NRs-I) associated with an increase of the diameters (from 6.0 to $8.1 \mathrm{~nm}$ for Co-NRs-I) were observed. This phenomenon was also observed for Co-NRs-II (lengths decrease from 114 to $107 \mathrm{~nm}$ and diameters increase from 5.8 to $7.7 \mathrm{~nm}$ ) after the catalytic test (Table S1), suggesting that a redistribution of cobalt took place during catalysis, as already observed for NRs prepared by the polyol process. ${ }^{37}$ Despite this, the NRs have retained their morphology. These results indicate that the slightly higher activity of Co-NRs-I results most likely from their lower ligand surface coverage. However, the presence of more ligand on the Co-NRs-II surface is not detrimental for their activity. This result is consistent with our previous work on nanoparticles synthesized by the polyol 

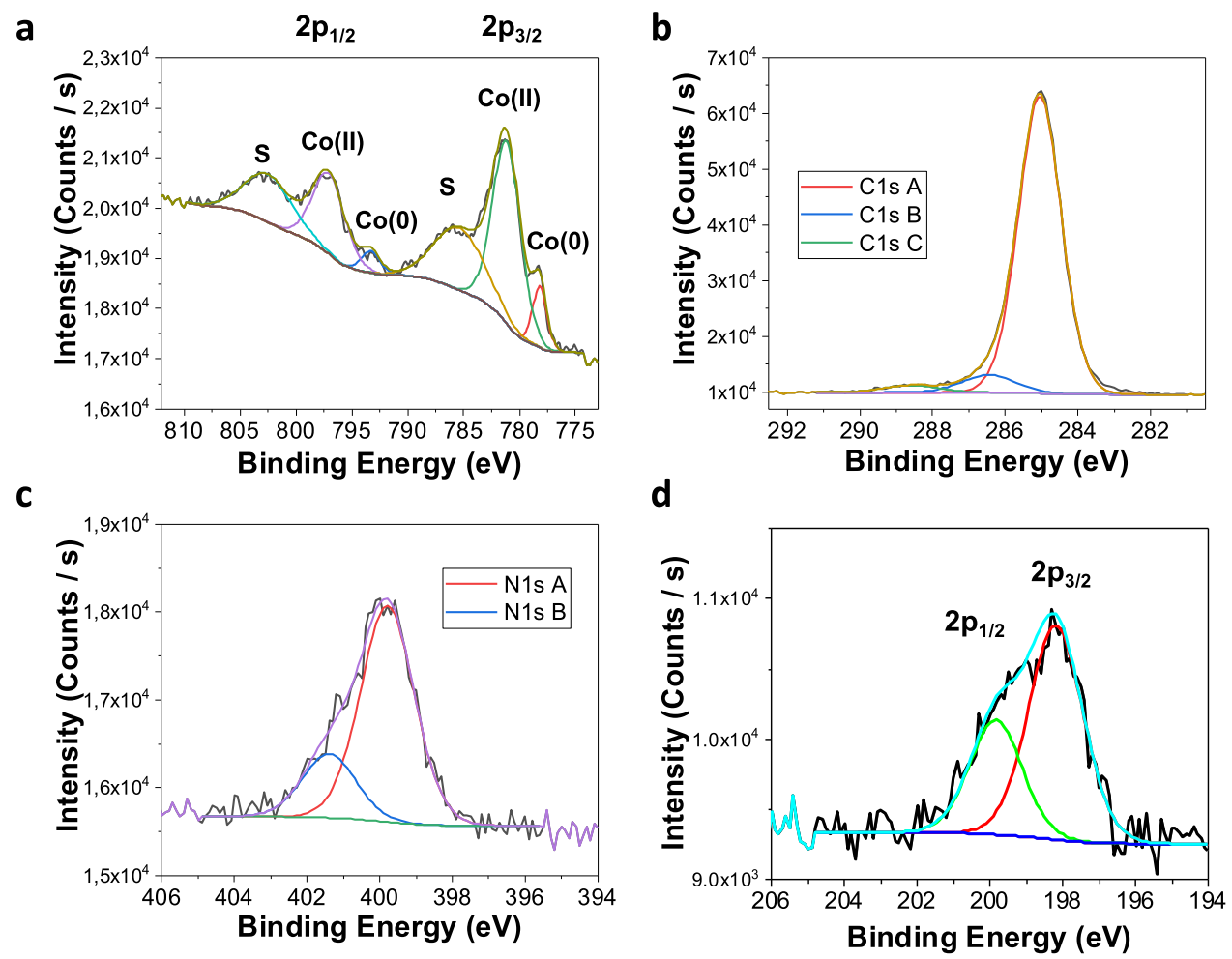

Figure 2. High-resolution X-ray photon electron spectra of Co nanoplatelets (Co-NPLs): (a) Co $2 \mathrm{p}_{3 / 2}$ and $2 \mathrm{p}_{1 / 2}$ peaks showing two contributions, $\mathrm{Co}(0)$ and $\mathrm{Co}(+\mathrm{II})$ and satellite peaks noted $S$. The binding energies of $\mathrm{Co} 2 \mathrm{p}_{3 / 2}$ are 778.1 and $781.1 \mathrm{eV}$ for $\mathrm{Co}(0)$ and $\mathrm{Co}(+\mathrm{II})$, respectively. (b) $\mathrm{C} 1$ s peak showing three contributions at the binding energies of 285.0, 286.4, and $288.6 \mathrm{eV}$. (c) N 1s peak showing two contributions at the binding energies of 399.8 and $401.4 \mathrm{eV}$, corresponding to $\mathrm{N}$ atoms belonging to amide and ammonium, respectively. (d) $\mathrm{Cl} 2 \mathrm{p}_{3 / 2}$ and $2 \mathrm{p}_{1 / 2}$ peaks.

method, where the catalysts were active, provided that the coverage by carboxylate ligands remained below $4 \mathrm{mg} \mathrm{m}^{-2}$. For the Co-NRs-I and Co-NRs-II, the measurements show that this condition is fulfilled (Table 1).

The nature of the capping ligands could, therefore, account for the striking difference between nanorods and nanoplatelets. Indeed, apart from LA and HDA, which are common ligands for both Co-NRs and Co-NPLs, $\mathrm{Cl}$ and $\mathrm{PPh}_{3}$ could also be present on the surface of Co-NPLs. IR spectrometry could provide useful information on the presence of some of these ligands in the NPs samples; however, due to the reduced ligand content, no exploitable IR spectra could be obtained. To determine the nature of the capping ligand, we conducted an XPS survey scan of Co-NPLs and Co $2 \mathrm{p}, \mathrm{C} 1 \mathrm{~s}, \mathrm{~N} \mathrm{1s}$, and Cl 2p peaks were detected (Figure $2 \mathrm{a}-\mathrm{d}$, respectively). The Co $2 \mathrm{p}$ peaks exhibited two contributions centered at 778.1 and 781.1 $\mathrm{eV}$ for $\mathrm{Co}(0)$ and $\mathrm{Co}(+\mathrm{II})$, respectively (Figure $2 \mathrm{a}$ ). The absence of $\mathrm{P} 2 \mathrm{p}$ peak is notable, showing that the phosphine present in the cobalt precursor does not remain adsorbed on the Co-NPLs surface. The $\mathrm{N}$ 1s high-resolution spectrum revealed two contributions centered at 401.4 and $399.8 \mathrm{eV}$ corresponding to $\mathrm{N}$ atoms of ammonium cation and amide group (Figure 2c). Thus, the highest-energy peak points toward the presence of hexadecylammonium chloride. The peak at $399.8 \mathrm{eV}$ falls in between the binding energies of nitrogen of hexadecylamine $(399 \mathrm{eV})$ and of the ammonium cation $(401 \mathrm{eV})$. This intermediate value is interpreted as the binding energy of $\mathrm{N}$ atoms of the amide, ${ }^{38}$ resulting from the condensation of lauric acid and hexadecylamine. ${ }^{39}$ The C 1s high-resolution spectrum revealed three peaks centered at 285.0, 286.4, and $288.6 \mathrm{eV}$, corresponding to the binding energy of $\mathrm{C}$ atoms of the aliphatic chains, of the ones in the $\alpha$ - position of carbonyl groups, and of carboxylate and/or the amide groups. The atomic ratio $\mathrm{Cl} / \mathrm{N}_{\text {ammonium }}$ deduced from the relative intensity and cross section of the two peaks is found to be 1.75. It is thus likely that a significant amount of $\mathrm{Cl}$ atoms is adsorbed on the Co-NPLs surface.

To verify whether $\mathrm{Cl}$ acts as a poison for the catalyst, a simple catalytic test was performed using Co-NRs-II in which $89 \mu \mathrm{mol}$ of hexadecylamonium chloride (HDA. $\mathrm{HCl}$ ) was added in the reaction medium (Co-NRs-II-HDA-HCl, Table 2 , entry $\left.4, n_{\mathrm{HDA} \cdot \mathrm{HCl}} / m_{\mathrm{NPs}}=4.67 \mathrm{mmol}_{\mathrm{HDA} \cdot \mathrm{HCl}} \mathrm{g}_{\mathrm{NPs}}{ }^{-1}\right)$. As it can be seen in Table 2 (entry 4, Co-NRs-II-HDA.HCl), the activity was entirely suppressed and TEM analysis of the spent catalyst revealed a drastic modification of the morphology and severe agglomeration of ill-shaped nanoparticles (Figure S6). $\mathrm{Cl}$ is thus detrimental to the activity as well as to the stability of the nanorods under the conditions employed in the catalytic tests. We therefore assume that the main reason for the lack of activity of the Co-NPLs is due to the presence of $\mathrm{Cl}$ on their surfaces.

Interestingly, the addition of $89 \mu \mathrm{mol}$ of $\mathrm{HDA}$ in the catalytic reaction medium did not have any impact on the CoNRs-II performance (Co-NRs-II-HDA, Table 2, entry 5, $\left.\mathrm{n}_{\mathrm{HDA}} / \mathrm{m}_{\mathrm{NPs}}=4.67 \mathrm{mmol}_{\mathrm{HDA}} \mathrm{g}_{\mathrm{NPs}}{ }^{-1}\right)$. However, as in the case of $\mathrm{HDA} \cdot \mathrm{HCl}$, the addition of the same amount of LA completely suppressed the catalytic activity of those nanorods (Co-NRsII-LA-4.7, Table 2, entry 6). Nevertheless, it is worth noting that the morphology remained intact, despite the slight modification of the length and the diameter observed, which was systematic for all samples after catalysis (Table S1). The LA amount was then gradually reduced in three other catalytic tests (Table 2, entries 7-9), to assess a limit value of externally added ligand at which the activity is conserved. This occurred 
Table 3. TGA, Elemental Analysis, and Catalytic Results for Pristine Co-NRs-I, Co-NRs-I-HDA-Ex, and Co-NRs-I-LA-Ex ${ }^{a}$

\begin{tabular}{lccccccc}
\multicolumn{1}{c}{ catalyst } & \% ligands $(\mathrm{wt} \%)$ & $\% \mathrm{~N}(\mathrm{wt} \%)$ & $\mathrm{N} / \mathrm{C}$ at $\times 100$ & ligand coverage $\left(\mathrm{mg} \mathrm{m}^{-2}\right)$ & $X(\%)$ & $\mathrm{S}(\%)$ & $\mathrm{TON}(/ 24 \mathrm{~h})$ \\
\hline Co-NRs-I & 12.9 & 0.34 & 3.0 & 1.7 & 85 & $>99.99$ & 920 \\
Co-NRs-I-HDA-Ex & 16.9 & 0.45 & 3.4 & 2.3 & 71 & $>99.99$ & 780 \\
Co-NRs-I-LA-Ex & 12.7 & 0.23 & 1.7 & 1.6 & 60 & $>99.99$ & 660
\end{tabular}

${ }^{a_{T}}$ The ligand content was derived from TGA. The ligand coverage was calculated based on an SSA of $89 \mathrm{~m}^{2} \mathrm{~g}^{-1}$ for the three samples. Reaction conditions: $25 \mathrm{mg}$ of catalyst, substrate: $0.95 \mathrm{~mol} \mathrm{~L}{ }^{-1} 2$-octanol, solvent: decane, $24 \mathrm{~h}, 145^{\circ} \mathrm{C}, V_{\text {total }}=45 \mathrm{~mL}$. X: conversion, $S$ : selectivity to 2 octanone, TON $(/ 24 \mathrm{~h})$ : turnover number $\left(\mathrm{mol}_{\text {alcohol }} \mathrm{mol}_{\text {surface Co }}{ }^{-1}\right)$ after $24 \mathrm{~h}, \pm 75 \mathrm{~mol}_{\text {alcohol }}$ mol $_{\text {surface Co }}{ }^{-1}$; $\% \mathrm{~N}$ : elemental analysis-derived wt \% of $\mathrm{N} ; \mathrm{N} / \mathrm{C}$ at $\times 100: \mathrm{N} / \mathrm{C}$ atomic ratio derived from elemental analysis, multiplied by 100 .

when only $4 \mu \mathrm{mol}$ of LA was added to the reaction (Co-NRsII-LA-0.2, $\left.n_{\mathrm{LA}} / m_{\mathrm{NPs}}=0.23 \mathrm{mmol}_{\mathrm{LA}} \mathrm{g}_{\mathrm{NPs}}{ }^{-1}\right)$. These experiments indicate that while HDA does not impact the surface reactivity for this catalytic reaction, even in a large amount, LA plays a negative role above a threshold.

To better understand the surface chemistry and its impact on the catalytic activity of the Co NRs, in another series of experiments, ligand exchanges with HDA and LA were performed before the catalytic testing. In this case (see experimental part), an excess of ligand was added to a suspension of Co-NRs-I, the nanorods were left under stirring overnight at room temperature to allow the exchange process to take place, and then washed to remove the excess of weakly bounded ligands. This procedure was repeated twice. Co-NRsI after ligand exchange with HDA and LA are named Co-NRsI-HDA-Ex and Co-NRs-I-LA-Ex, respectively. TEM analysis showed that ligand exchange did not impact the morphology (Figure S7 and Table S1). Other characterization results, i.e., the ligand content, elemental analysis-derived information, as well as the catalytic results for the pristine Co-NRs-I containing their native ligands and samples after ligand exchange, are shown in Table 3. The results confirm the negative impact of LA and the neutral role of HDA in the catalytic activity of the nanorods. Nevertheless, Co-NRs-I-LAEx showed a non-negligible activity, despite the fact that ligand exchange was performed with an excess of LA $\left(n_{\mathrm{LA}} / m_{\mathrm{NPs}}=3.8\right.$ $\left.\mathrm{mmol}_{\mathrm{LA}} \mathrm{g}_{\mathrm{NPs}}{ }^{-1}\right)$. This is surprising if we consider that the external addition of only $0.58 \mathrm{mmol}_{\mathrm{LA}} \mathrm{g}_{\mathrm{NPs}}{ }^{-1}$ in the catalytic reaction was enough to kill the catalytic activity of Co-NRs-IILA-0.6 (Table 2, entry 8).

To explain this phenomenon, the surface state of the catalysts and the efficiency of the ligand exchange procedure were investigated. The XPS survey scans of the pristine CoNRs-I (Figure 3) exhibit Co 2p, C 1s, and N 1s peaks. The N $1 \mathrm{~s}$ high-resolution spectrum revealed a main peak centered at $399.8 \mathrm{eV}$. As for Co-NPLs, this value is interpreted as the binding energy of $\mathrm{N}$ atoms of the amide resulting from the condensation of lauric acid and hexadecylamine. ${ }^{39}$ A minor peak ( $20 \%$ of the $\mathrm{N} 1 \mathrm{~s}$ signal) is also observed at $401.5 \mathrm{eV}$, which is attributed to the presence of hexadecylammonium ions. The $\mathrm{C} 1 \mathrm{~s}$ high-resolution spectrum revealed three peaks centered at 284.7, 286.1, and $288.2 \mathrm{eV}$, corresponding to the binding energy of $\mathrm{C}$ atoms of the aliphatic chains in $\alpha$ position of the carbonyl groups, and of the carboxylate and/or the amide groups, respectively. The XPS spectra of commercial laurylamide and Co nanorods coated with laurate ions only are given in the Supplementary Information ${ }^{37}$ (Figure S8); in both cases, they show three peaks very close in energy to the binding energies recorded on Co-NRs-I. Thus, the C 1s XPS spectrum does not allow us to distinguish between laurate ions and amide.
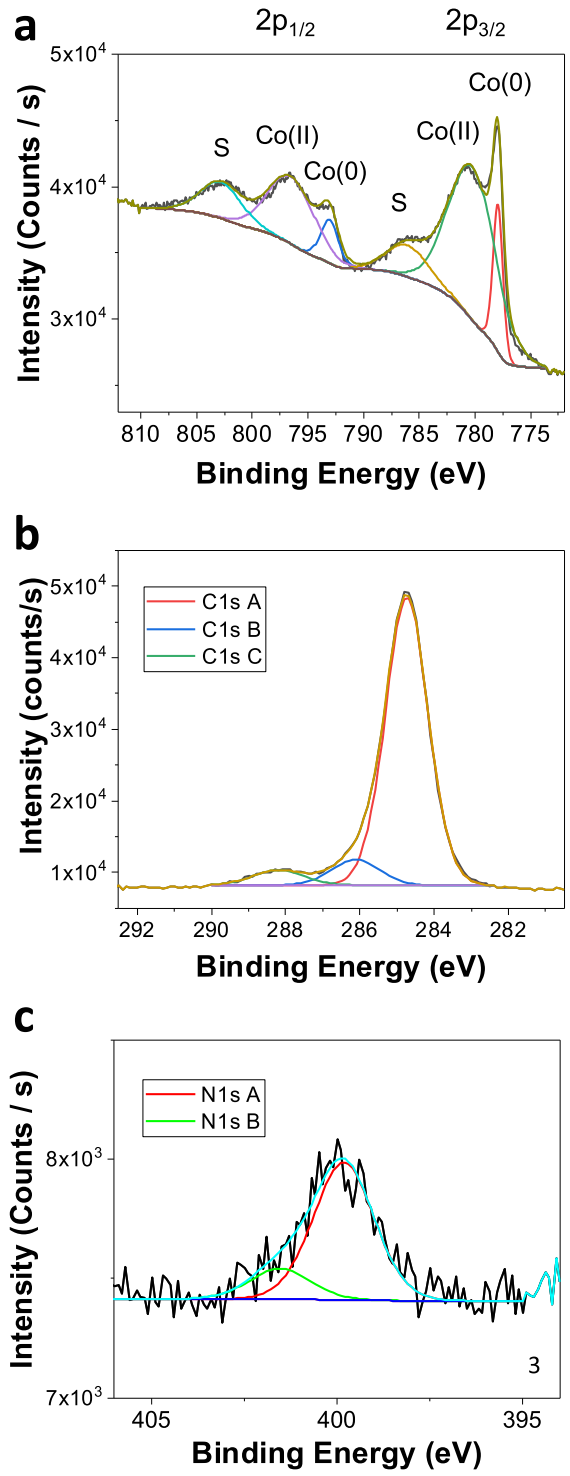

Figure 3. High-resolution X-ray photon electron spectra of Co-NRsI: (a) Co $2 \mathrm{p}_{3 / 2}$ and Co $2 \mathrm{p}_{1 / 2}$ peaks showing two contributions, $\mathrm{Co}(0)$ and $\mathrm{Co}(+\mathrm{II})$ and satellite peaks noted $\mathrm{S}$. The binding energies Co $2 \mathrm{p}_{3 / 2}$ are 777.9 and $780.2 \mathrm{eV}$ for $\mathrm{Co}(0)$ and $\mathrm{Co}(+\mathrm{II})$, respectively. (b) $\mathrm{C} 1 \mathrm{~s}$ peak showing three contributions at the binding energies of 284.7, 286.1, and $288.2 \mathrm{eV}$. (c) $\mathrm{N} 1 \mathrm{~s}$ peak showing the main contribution at the binding energy of $399.8 \mathrm{eV}$ and a minor contribution at $401.5 \mathrm{eV}$.

The atomic ratio $\mathrm{N} / \mathrm{C}=0.0297$ (Table 3, entry 1) calculated by the chemical analysis is lower than the expected value in the pure amide $(\mathrm{N} / \mathrm{C}=0.0357)$, showing that the organic residue on the surface of the Co NRs corresponds to a mixture of laurate and $N$-hexadecyl laurylamide. The Co $2 \mathrm{p}_{3 / 2}$ 
peak is a sum of two contributions centered at 777.9 and 780.2 $\mathrm{eV}$ for $\mathrm{Co}(0)$ and $\mathrm{Co}(+\mathrm{II})$, respectively. The XPS spectrum is compatible with a metallic core and a thin carboxylate layer structure, as it was the case for cobalt nanorods prepared by the polyol method. However, the $\mathrm{Co}(0)$ component was hardly observable in that case, likely because of a thicker layer of cobalt oxide. ${ }^{31}$ After ligand exchange with HDA in toluene, the TGA of the dried powder revealed a slightly higher organic content for Co-NRs-I-HDA-Ex compared to Co-NRs-I (Figure S9 and Table 3). The XPS survey scans of the Co NRs after ligand exchange with HDA (Co-NRs-I-HDA-Ex) exhibited Co 2 p, C 1s, and N 1s peaks. The high-resolution Xray photon electron spectra (Figure S10) are very similar to the ones of the pristine Co-NRs-I. The binding energy of the Co $2 p$ peak is similar in both cases, showing that the ligand exchange did not oxidize the cobalt nanorods. The binding energy of $\mathrm{N} 1 \mathrm{~s}$ was found to be $399.6 \mathrm{eV}$, i.e., slightly shifted to low energy. The $\mathrm{C} 1 \mathrm{~s}$ peak is the sum of three contributions at the binding energies of $284.7,286.3$, and $288.2 \mathrm{eV}$. We can note however that the relative contribution of the $\mathrm{C} 1 \mathrm{~s}$ at 288.2 $\mathrm{eV}$ has decreased after the ligand exchange, in agreement with a partial substitution of the amide by amine. This is corroborated by the higher $\mathrm{N} / \mathrm{C}$ ratio calculated from elemental analysis (Table 3, entry 2). After exchange with LA, TGA of Co-NRs-I-LA-Ex (Figure S9) revealed almost the same amount of organic molecules at the surface of the rods as before ligand exchange. The XPS results (Figure S11) were very similar to the ones of the pristine sample (Figure 3 ). The binding energy of the Co $2 \mathrm{p}$ peak is similar to the one of CoNRs-I, showing that the ligand exchange did not oxidize the cobalt nanorods. The binding energy of $\mathrm{N} 1 \mathrm{~s}$ was found to be $400.1 \mathrm{eV}$. The C 1s XPS spectrum can be interpreted as resulting from a mixture of laurate and $N$-hexadecyl laurylamide at the surface of the rods (Figure S11). The chemical analysis revealed, however, that the atomic $\mathrm{N} / \mathrm{C}$ ratio decreased from 3.0 to $1.7 \%$ after ligand exchange, revealing a partial substitution of the amide by lauric acid on the surface of the rods. The relative molar ratio of LA and amide was estimated from the chemical analysis to increase from 35:65 before exchange to $72: 28$ after ligand exchange.

To summarize, the organic shell of the Co NRs is composed of hexadecylammonium laurate and $N$-hexadecyl laurylamide, the condensation product of the two ligands used for the synthesis of nanorods. $N$-hexadecyl laurylamide is likely weakly coordinated or adsorbed onto the surface since it is partially displaced by an excess of HDA or LA. A small amount of LA halts the catalytic activity of NRs when directly added in the catalytic tests, whereas this effect is much weaker when an excess of LA is used for ligand exchange. Since the ligand exchange procedure was performed at room temperature, only a small amount of LA was able to replace $N$-hexadecyl laurylamide, before being washed away. It is also possible that the low solubility of $N$-hexadecyl laurylamide contributes to its persistence on the nanorods. When LA is directly added in the catalytic reaction at $145{ }^{\circ} \mathrm{C}$, the replacement is complete. Indeed, it is likely that $N$-hexadecyl laurylamide desorbs more easily from the surface of the nanorod at this higher temperature, allowing a free access to the incoming LA, which is a better ligand than the amide. ${ }^{39}$ Therefore, at a high temperature, the whole LA amount present in solution interacts with the cobalt surface, hence blocking the active sites.

\section{CONCLUSIONS}

Co nano-objects of different shapes and surface chemistries, prepared via the organometallic route, were tested for acceptor-less dehydrogenation reactions for the first time. Co NRs were obtained by the reduction of $[\mathrm{Co}\{\mathrm{N}$ $\left.\left(\mathrm{SiMe}_{3}\right)_{2}\right\}_{2}($ thf $\left.)\right]$ under $\mathrm{H}_{2}$ in the presence of LA and HDA. Changing the precursor to $\left[\mathrm{CoCl}\left(\mathrm{PPh}_{3}\right)_{3}\right](\mathrm{Ph}=$ phenyl $)$ drastically affected the morphology, and NPLs were obtained for the first time by this method. During the nanoparticle formation, part of the LA and HDA condensates to $N$ hexadecyl laurylamide, which acts as an additional surface stabilizing agent. The postsynthesis washing procedure removes only part of the stabilizing ligands, leaving behind, in the case of NRs, hexadecylammonium laurate and $N$ hexadecyl laurylamide, and in the case of NPLs, hexadecylammonium chloride and $N$-hexadecyl laurylamide. Co-NRs-I were active and fully selective toward the dehydrogenation of 2 -octanol to 2-octanone, and up to $85 \%$ conversion was observed after $24 \mathrm{~h}$. Co NRs with a higher content of ligand (Co-NRs-II) as a result of less extensive washing were slightly less active. On the other hand, Co-NPLs were inactive due to the presence of chloride. The deleterious effect of chloride was confirmed by an independent experiment, in which the Co NR catalytic activity was completely suppressed upon $\mathrm{HDA} / \mathrm{HCl}$ addition in the catalytic reaction medium. The direct addition of HDA in the catalytic reaction medium was not detrimental to the NRs, as HDA coordinates weakly to the surface. On the contrary, addition into the catalytic reaction medium of even small quantities of LA, which provides strongly coordinating laurate ligands, impaired the catalytic performance. Interestingly, the catalytic performance of the Co NRs was not strongly affected after a standard ligand exchange procedure at room temperature as only a small amount of LA was able to displace the amide ligand at this low temperature. For the Co NRs prepared in a mixture of HDA and LA, occupation of the Co surface mostly by amine and amide ligands allows liberation during catalysis of a higher number of active sites compared to laurate-only-capped Co. Therefore, in addition to the nature and the amount of the capping ligands, the dynamics between the ligands and the reaction substrate (and/ or reaction intermediates) taking place under catalytic reaction conditions are also an important parameter that can affect nanoparticle surface accessibility.

\section{AUTHOR INFORMATION}

\section{Corresponding Authors}

Katerina Soulantica - Université de Toulouse, LPCNO CNRS, INSA, UPS UMR 5215, 31077 Toulouse, France; ○ orcid.org/0000-0003-3033-1620; Email: ksoulant@insatoulouse.fr

Noémie Perret - Univ Lyon, Université Claude Bernard Lyon 1, CNRS, UMR5256, IRCELYON, 69626 Villeurbanne, France; 이이.org/0000-0003-4976-5189; Email: noemie.perret@ircelyon.univ-lyon1.fr 


\section{Authors \\ Kamila Kaźmierczak - Univ Lyon, Université Claude Bernard Lyon 1, CNRS, UMR5256, IRCELYON, 69626 Villeurbanne, France; Univ Lyon, ENS de Lyon, CNRS UMR 5182, Université Claude Bernard Lyon 1, Laboratoire de Chimie, 69342 Lyon, France \\ Deliang Yi - Université de Toulouse, LPCNO CNRS, INSA, UPS UMR 5215, 31077 Toulouse, France \\ Arnaud Jaud - Université de Toulouse, LPCNO CNRS, INSA, UPS UMR 5215, 31077 Toulouse, France \\ Pier-Francesco Fazzini - Université de Toulouse, LPCNO CNRS, INSA, UPS UMR 5215, 31077 Toulouse, France \\ Marta Estrader - Université de Toulouse, LPCNO CNRS, INSA, UPS UMR 5215, 31077 Toulouse, France \\ Guillaume Viau - Université de Toulouse, LPCNO CNRS, INSA, UPS UMR 5215, 31077 Toulouse, France; (1) orcid.org/0000-0001-7062-4183 \\ Philippe Decorse - Université de Paris, ITODYS UMR 7086, 75013 Paris, France \\ Jean-Yves Piquemal - Université de Paris, ITODYS UMR 7086, 75013 Paris, France \\ Carine Michel - Univ Lyon, ENS de Lyon, CNRS UMR 5182, Université Claude Bernard Lyon 1, Laboratoire de Chimie, 69342 Lyon, France; ㅇo orcid.org/0000-0002- 4501-7194 \\ Michèle Besson - Univ Lyon, Université Claude Bernard Lyon 1, CNRS, UMR5256, IRCELYON, 69626 Villeurbanne, France}

\section{Author Contributions}

The manuscript was written through contributions of all authors. All authors have given approval to the final version of the manuscript.

\section{Notes}

The authors declare no competing financial interest.

\section{ACKNOWLEDGMENTS}

D.Y. thanks the "CaSh" project for financial support through the EUR grant NanoX no. ANR-17-EURE-0009 in the framework of the "Programme des Investissements d'Avenir". A.J. thanks the LABEX-NEXT for the project "RodUp". M.E. thanks the EC (HyCoRod project, H2020-MSCA-IF 2015 No. 704098). K.K., J.-Y.P., C.M., M.B., and N.P. thank the ANR agency for the founding of TANOPOL project (ANR-15CE07-0011-01). The French ANR (Agence Nationale de la Recherche) and CGI (Commissariat à l'Investissement d'Avenir) are gratefully acknowledged for their financial support of this work through the Labex SEAM grant (nos. ANR 11 LBX 086 and ANR 11 IDEX 05 02). The authors acknowledge the access to the XPS platform of ITODYS lab (Paris University) that is supported by the Ile-de-France Regional Counsil through the SESAME grant (No. 16016303).

\section{REFERENCES}

(1) Somorjai, G. A.; Li, Y. Selective Nanocatalysis of Organic Transformation by Metals: Concepts, Model Systems, and Instruments. Top. Catal. 2010, 53, 832-847.

(2) An, K.; Somorjai, G. A. Size and Shape Control of Metal Nanoparticles for Reaction Selectivity in Catalysis. ChemCatChem 2012, 4, 1512-1524.
(3) Xia, Y.; Xiong, Y.; Lim, B.; Skrabalak, S. E. Shape-Controlled Synthesis of Metal Nanocrystals: Simple Chemistry Meets Complex Physics? Angew. Chem., Int. Ed. 2009, 48, 60-103.

(4) Pal, J.; Pal, T. Faceted Metal and Metal Oxide Nanoparticles: Design, Fabrication and Catalysis. Nanoscale 2015, 7, 14159-14190.

(5) Sharma, N.; Ojha, H.; Bharadwaj, A.; Pathak, D. P.; Sharma, R. K. Preparation and Catalytic Applications of Nanomaterials: A Review. RSC Adv. 2015, 5, 53381-53403.

(6) Cargnello, M. Colloidal Nanocrystals as Building Blocks for Well-Defined Heterogeneous Catalysts. Chem. Mater. 2019, 31, 576596.

(7) Dai, Y.; Wang, Y.; Liu, B.; Yang, Y. Metallic Nanocatalysis: An Accelerating Seamless Integration with Nanotechnology. Small 2015, $11,268-289$.

(8) Jin, R. The Impacts of Nanotechnology on Catalysis by Precious Metal Nanoparticles. Nanotechnol. Rev. 2012, 1, 31-56.

(9) Niu, Z.; Li, Y. Removal and Utilization of Capping Agents in Nanocatalysis. Chem. Mater. 2014, 26, 72-83.

(10) Rossi, L. M.; Fiorio, J. L.; Garcia, M. A. S.; Ferraz, C. P. The Role and Fate of Capping Ligands in Colloidally Prepared Metal Nanoparticle Catalysts. Dalton Trans. 2018, 47, 5889-5915.

(11) Stowell, C. A.; Korgel, B. A. Iridium Nanocrystal Synthesis and Surface Coating-Dependent Catalytic Activity. Nano Lett. 2005, 5, 1203-1207.

(12) Martínez-Prieto, L. M.; Carenco, S.; Wu, C. H.; Bonnefille, E.; Axnanda, S.; Liu, Z.; Fazzini, P. F.; Philippot, K.; Salmeron, M.; Chaudret, B. Organometallic Ruthenium Nanoparticles as Model Catalysts for CO Hydrogenation: A Nuclear Magnetic Resonance and Ambient-Pressure X-Ray Photoelectron Spectroscopy Study. ACS Catal. 2014, 4, 3160-3168.

(13) Campisi, S.; Schiavoni, M.; Chan-Thaw, C.; Villa, A. Untangling the Role of the Capping Agent in Nanocatalysis: Recent Advances and Perspectives. Catalysts 2016, 6, No. 185.

(14) Huang, W.; Hua, Q.; Cao, T. Influence and Removal of Capping Ligands on Catalytic Colloidal Nanoparticles. Catal. Lett. 2014, 144, 1355-1369.

(15) Tschan, M. J.-L.; Diebolt, O.; van Leeuwen, P. W. N. M. Ruthenium Metal Nanoparticles in Hydrogenation: Influence of Phosphorus-Ligands. Top. Catal. 2014, 57, 1054-1065.

(16) Jin, L.; Liu, B.; Duay, S.; He, J. Engineering Surface Ligands of Noble Metal Nanocatalysts in Tuning the Product Selectivity. Catalysts 2017, 7, No. 44.

(17) Pang, S. H.; Schoenbaum, C. A.; Schwartz, D. K.; Medlin, J. W. Directing Reaction Pathways by Catalyst Active-Site Selection Using Self-Assembled Monolayers. Nat. Commun. 2013, 4, No. 2448.

(18) Mark, L. O.; Zhu, C.; Medlin, J. W.; Heinz, H. Understanding the Surface Reactivity of Ligand-Protected Metal Nanoparticles for Biomass Upgrading. ACS Catal. 2020, 10, 5462-5474.

(19) Maligal-Ganesh, R. V.; Brashler, K.; Luan, X.; Goh, T. W.; Gustafson, J.; Wu, J.; Huang, W. Enhanced Chemoselectivity in Pt$\mathrm{Fe} @ \mathrm{mSiO}_{2}$ Bimetallic Nanoparticles in the Absence of Surface Modifying Ligands. Top. Catal. 2018, 61, 940-948.

(20) Kazmierczak, K.; Pinel, C.; Loridant, S.; Besson, M.; Michel, C.; Perret, N. Supported Cobalt Catalysts for Acceptorless Alcohol Dehydrogenation. ChemPlusChem 2020, 85, 1315-1324.

(21) Shimizu, K.; Kon, K.; Seto, M.; Shimura, K.; Yamazaki, H.; Kondo, J. N. Heterogeneous Cobalt Catalysts for the Acceptorless Dehydrogenation of Alcohols. Green Chem. 2013, 15, 418-424.

(22) Kaźmierczak, K.; Ramamoorthy, R. K.; Moisset, A.; Viau, G.; Viola, A.; Giraud, M.; Peron, J.; Sicard, L.; Piquemal, J.-Y.; Besson, M.; et al. Importance of the Decoration in Shaped Cobalt Nanoparticles in the Acceptor-Less Secondary Alcohol Dehydrogenation. Catal. Sci. Technol. 2020, 10, 4923-4937.

(23) Viola, A.; Peron, J.; Kazmierczak, K.; Giraud, M.; Michel, C.; Sicard, L.; Perret, N.; Beaunier, P.; Sicard, M.; Besson.; et al. Unsupported Shaped Cobalt Nanoparticles as Efficient and Recyclable Catalysts for the Solvent-Free Acceptorless Dehydrogenation of Alcohols. Catal. Sci. Technol. 2018, 8, 562-572. 
(24) Viola, A.; Peron, J.; Giraud, M.; Sicard, L.; Chevillot-Biraud, A.; Decorse, P.; Nowak, S.; Beaunier, P.; Lang, P.; Piquemal, J.-Y. On the Importance of the Crystalline Surface Structure on the Catalytic Activity and Stability of Tailored Unsupported Cobalt Nanoparticles for the Solvent-Free Acceptor-Less Alcohol Dehydrogenation. J. Colloid Interface Sci. 2020, 573, 165-175.

(25) Ramamoorthy, R. K.; Viola, A.; Grindi, B.; Peron, J.; Gatel, C.; Hytch, M.; Arenal, R.; Sicard, L.; Giraud, M.; Piquemal, J.-Y.; et al. One-Pot Seed-Mediated Growth of Co Nanoparticles by the Polyol Process: Unraveling the Heterogeneous Nucleation. Nano Lett. 2019, 19, 9160-9169.

(26) Fiévet, F.; Ammar-Merah, S.; Brayner, R.; Chau, F.; Giraud, M.; Mammeri, F.; Peron, J.; Piquemal, J.-Y.; Sicard, L.; Viau, G. The Polyol Process: A Unique Method for Easy Access to Metal Nanoparticles with Tailored Sizes, Shapes and Compositions. Chem. Soc. Rev. 2018, 47, 5187-5233.

(27) Amiens, C.; Chaudret, B.; Ciuculescu-Pradines, D.; Collière, V.; Fajerwerg, K.; Fau, P.; Kahn, M.; Maisonnat, A.; Soulantica, K.; Philippot, K. Organometallic Approach for the Synthesis of Nanostructures. New J. Chem. 2013, 37, 3374-3401.

(28) Green, M. Organometallic Based Strategies for Metal Nanocrystal Synthesis. Chem. Commun. 2005, 3002-3011.

(29) Cormary, B.; Dumestre, F.; Liakakos, N.; Soulantica, K.; Chaudret, B. Organometallic Precursors of Nano-Objects, a Critical View. Dalton Trans. 2013, 42, 12546-12553.

(30) Dumestre, F.; Chaudret, B.; Amiens, C.; Respaud, M.; Fejes, P.; Renaud, P.; Zurcher, P. Unprecedented Crystalline Super-Lattices of Monodisperse Cobalt Nanorods. Angew. Chem., Int. Ed. 2003, 42, 5213-5216.

(31) Cormary, B.; Li, T.; Liakakos, N.; Peres, L.; Fazzini, P.-F.; Blon, T.; Respaud, M.; Kropf, A. J.; Chaudret, B.; Miller, J. T.; et al. Concerted Growth and Ordering of Cobalt Nanorod Arrays as Revealed by Tandem in Situ SAXS-XAS Studies. J. Am. Chem. Soc. 2016, 138, 8422-8431.

(32) Liakakos, N.; Cormary, B.; Li, X.; Lecante, P.; Respaud, M.; Maron, L.; Falqui, A.; Genovese, A.; Vendier, L.; Koönis, S.; et al. The Big Impact of a Small Detail: Cobalt Nanocrystal Polymorphism as a Result of Precursor Addition Rate during Stock Solution Preparation. J. Am. Chem. Soc. 2012, 134, 17922-17931.

(33) Comesaña-Hermo, M.; Ciuculescu, D.; Li, Z.-A.; Stienen, S.; Spasova, M.; Farle, M.; Amiens, C. Stable Single Domain Co Nanodisks: Synthesis, Structure and Magnetism. J. Mater. Chem. 2012, 22, 8043-8047.

(34) Meziane, L.; Salzemann, C.; Aubert, C.; Gérard, H.; Petit, C.; Petit, M. Hcp Cobalt Nanocrystals with High Magnetic Anisotropy Prepared by Easy One-Pot Synthesis. Nanoscale 2016, 8, 1864018645 .

(35) González-Gálvez, D.; Nolis, P.; Philippot, K.; Chaudret, B.; van Leeuwen, P. W. N. M. Phosphine-Stabilized Ruthenium Nanoparticles: The Effect of the Nature of the Ligand in Catalysis. ACS Catal. 2012, 2, 317-321.

(36) Soulantica, K.; Maisonnat, A.; Fromen, M.-C.; Casanove, M.-J.; Chaudret, B. Spontaneous Formation of Ordered 3D Superlattices of Nanocrystals from Polydisperse Colloidal Solutions. Angew. Chem., Int. Ed. 2003, 42, 1945-1949.

(37) Viola, A.; Peboscq, M.; Peron, J.; Giraud, M.; Sicard, L.; Ramamoorthy, R. K.; Azeredo, B.; Nowak, S.; Decorse, P.; Viau, G.; et al. Impact of Noble-Metals on the Catalytic Stability of Cobalt Nanoparticles for the Acceptorless Dehydrogenation of Alcohols. Catal. Today 2019, 333, 97-104.

(38) NIST X-ray Photoelectron Spectroscopy Database, NIST Standard Reference Database Number 20; 10.18434/T4T88K; National Institute of Standards and Technology: Gaithersburg, MD, 2000 (retrieved March 18, 2021).

(39) Wu, H.; Yang, Y.; Cao, Y. C. Synthesis of Colloidal UraniumDioxide Nanocrystals. J. Am. Chem. Soc. 2006, 128, 16522-16523. 